\title{
LA VOLUNTAD DE EVA: UN RECORRIDO CRÍTICO POR LA TRILOGÍA CINE DE JUAN MARTINI
}

\author{
Juan Ezequiel Rogna
}

\section{(c) ${ }_{\mathrm{EY}} \mathrm{NO} \mathrm{ND}_{\mathrm{ND}}$}

Doi: https://doi.org/10.15517/rfl.v45i2.39099

URL: https://revistas.ucr.ac.cr/index.php/filyling/index 



\title{
LA VOLUNTAD DE EVA: UN RECORRIDO CRÍTICO POR LA TRILOGÍA CINE DE JUAN MARTINI
}

\author{
EVA'S WILL: A CRITICAL REVIEW OF JUAN MARTINI'S \\ CINE (CINEMA) TRILOGY
}

\author{
Juan Ezequiel Rogna
}

\begin{abstract}
RESUMEN
En el presente trabajo analizaremos la configuración de Eva Perón desarrollada en Cine, una tríada novelística del escritor rosarino Juan Martini (1944). Partimos de la hipótesis según la cual los cambios acaecidos en Argentina durante la década pasada habrían propiciado el resurgimiento de la "potencialidad política" de Evita, aparentemente "conjurada" en los primeros años del presente siglo (Saítta, 2002). En sintonía con este fenómeno y apelando a la ficción literaria, Martini modeliza a una Eva en raudo pasaje hacia su radicalización política y su devenir mítico. De tal modo, su figura no queda subsumida en la leyenda negra anti-peronista, el discurso hagiográfico justicialista o el "artefacto" forjado por el show business (Soria, 2005); por el contrario, viene a representar la esencia del "mito peronista" (Casullo, 2008) a partir de la "hibridación" entre las "lógicas de representación" del Estado y de la industria cultural que el peronismo inauguró y que posibilitó el ingreso de Evita en la dimensión "legendaria" del "imaginario popular" (Rosano, 2006). Por otra parte, nos detendremos en la conformación subjetiva de Sivori, el cineasta que pretende filmar una errática trilogía fílmica sobre Eva Perón, para contrastar sus respectivas voluntades y sus dispares sentidos de trascendencia.

Palabras clave: Literatura y política; narrativa argentina contemporánea; Juan Martini; Eva Perón; mito peronista.

ABSTRACT

In this study we will analyze the construction of Eva Perón as developed in Cine (Cinema), a triad of novels by Rosario-born writer Juan Martini (1944). We will base this study on the hypothesis that the changes experienced by Argentina over the last decade may have promoted the resurgence of Evita's "political potentiality", apparently "warded off" during the first years of this century (Saítta, 2002). In sync with this phenomenon and relying on literary fiction, Martini models an Eva in swift transition towards her political radicalization and mythical fate. Thus, her image has not ended up subsumed under the black anti-Peronist legend, the Justicialist hagiographic pitch, or the "artifact" forged by show business (Soria 2005); on the contrary it has come to embody the essence of the "Peronist myth" (Casullo 2008) out of the "hybridization" between the "logics of representation" of the State and the cultural industry that Peronism founded and which enabled Evita's passage to the "legendary" dimension of "collective imagination" (Rosano 2006). We will additionally examine the subjective composition of Sivori, the film-maker who seeks to create an erratic film trilogy about Eva Perón, so as to contrast their respective wills and their dissimilar senses of transcendence. Keywords: Literature and politics; contemporary argentinian narrative; Juan Martini; Eva Perón; peronist myth.
\end{abstract}

Dr. Juan Ezequiel Rogna. Profesor Asistente en la cátedra de Literatura Argentina II de la Facultad de Filosofía y Humanidades. Miembro del proyecto de investigación "Literatura y política: construcción de identidades y configuraciones estéticas de lo popular en la narrativa argentina. 1960-2015”. Universidad Nacional de Córdoba. Argentina.

Correo electrónico: jerogna@gmail.com

Recepción: 14- 07- 18

Aceptación: 19- 08- 18 


\section{Introducción}

Desde su emergencia a mediados de la década de 1940, el peronismo significó una otredad política y cultural respecto de un país liberal en lo económico y conservador en lo político. La visibilización de los sujetos populares y sus manifestaciones culturales puso en cuestionamiento la hegemonía del paradigma culto-letrado-civilizado que, en la configuración de Estados nacionales como el argentino, estuvo estrechamente vinculado a la filosofía positivista y el imperio de la técnica. Los Estados modernos se erigieron, en efecto, como proyectos normalizadores o aniquiladores de la otredad cultural popular. En el caso específico de la Argentina, la dicotomía sarmientina civilización/barbarie sintetizó la voluntad letrada de establecer "alteridades radicales" . Así, el discurso civilizatorio decimonónico pretendió anular la amenaza del caos social implantando dispositivos que clausuraran al Otro, subalternizándolo en el campo discursivo y/o desplazándolo-eliminándolo físicamente en los dominios de la praxis política. El naciente sistema literario fue, entonces, terreno fértil para el desenvolvimiento de estrategias de auto-adscripción de aquellos individuos letrados-civilizados que buscaban identificarse con el canon cultural universal y distinguirse, consecuentemente, de los sujetos incultos-bárbaros vernáculos. De esta manera, la alteridad se concibió desde los primeros textos literarios como una relación agónica entre dos paradigmas culturales que solo podía ser resuelta a través de la eliminación de una u otra tesis: civilización $o$ barbarie, en los términos de Facundo (Sarmiento, 1979); el joven unitario o la turba federal, según "El matadero" (cuento fundacional escrito por Esteban Echeverría en 1838 y publicado en 1871 -1979-).

Por otra parte, el surgimiento del peronismo no puede desligarse de la figura gravitante de Eva Duarte de Perón, Evita, quien encarnó una total disrupción respecto del imaginario y la praxis del poder político precedente. De la mano de Eva, la "otredad popular" invadió el seno mismo de la institucionalidad republicana; pero a la vez, dentro del propio Movimiento Nacional Justicialista, ella representó un límite. Este límite se tradujo en el "fanatismo" que ella acabó exigiéndole al "pueblo puro" en su enfrentamiento con la oligarquía (Perón, 2012, p. 45); y si bien esa oligarquía fue identificada en Mi mensaje (el testamento político de Eva) como una "alteridad radical" respecto del peronismo, resultaba al mismo tiempo una amenaza para la constitución subjetiva de los propios peronistas, especialmente de los dirigentes políticos y sindicales.

Sin deseos ni posibilidades de agotar las innumerables aristas que conforman la efigie de Evita, podríamos afirmar que ninguna otra personalidad política de la historia Argentina generó al mismo tiempo tanto amor y tanto odio como Eva Perón, así como también tanta producción bibliográfica urdida alrededor de su figura. La proliferación de discursos biográficos, ensayísticos, artísticos y periodísticos sobre Evita ha generado un corpus con

1 Recogemos el concepto del filósofo francés Jean Baudrillard, quien lo delineó en La transparencia del mal (1991) contraponiéndolo al de "diferencia". Según Baudrillard, mientras esta se manifiesta como "absurdo derecho" y "fetichización” en las sociedades occidentales contemporáneas, convirtiéndose en una "alteridad negociable" (p. 139) o, según otros términos que nos permitimos, en un producto más dentro de las góndolas del mercado global, el "exotismo radical" y la alteridad que de él se deriva constituyen "una especie de fuerza de repulsión universal que se opone a la fuerza canónica de la atracción universal” (p. 150). De acuerdo con esta contraposición, Baudrillard agrega que a pesar de la ilusión del evolucionismo cosmopolita no existe solución a la Extrañeza, puesto que su condición eterna y radical es "la regla del mundo y no una ley" (p. 150).

Doi: https://doi.org/10.15517/rfl.v45i2.39099 / URL: https://revistas.ucr.ac.cr/index.php/filyling/index 
significativa gravitación dentro del campo cultural argentino. Si en el siglo XIX fue Juan Manuel de Rosas quien dio impulso a las plumas unitarias aglutinando un gran número de configuraciones literarias que elaboraron -sobre todo- su demonización, durante la segunda mitad del siglo XX y lo que va del XXI ha sido Evita la musa y depositaria de una producción escritural semejante; como si existiese un subyacente paralelismo entre Rosas y Juan Domingo Perón, en el plano político, y entre Rosas y Eva Perón, en el plano cultural ${ }^{2}$.

"Esa mujer", en efecto, sigue interviniendo en los debates de nuestro tiempo. Lo prueba el hecho de que, en la Argentina de los últimos años y dentro del vasto abanico de discursos que abordaron diferentes aspectos del peronismo y de sus figuras más emblemáticas, se destaca especialmente el tratamiento de Eva. Por un lado, existe una nutrida producción crítica que abordó recientemente y desde múltiples perspectivas a Eva Perón, fundamentalmente en el vaivén entre el "mundo de la política" y el "mundo del espectáculo" (Sebreli, 2008, p. 37).

Cabe señalar, tal como lo hace Ana María Amar Sánchez desde el "Prólogo" a un libro ensayístico de Alejandro Susti González, que la "moda Eva” generada durante la década menemista fue "producto quizá de un deseo por regresar al origen de una historia que se precipitaba en los azarosos -infames- años '90 [y que] produjo también un considerable interés en la crítica" (2007, p. 9). En efecto, durante la década del '90, a la par del izamiento de las banderas justicialistas por parte del gobierno de Carlos Saúl Menem (1989-1999), la subordinación del Estado a los intereses del imperio norteamericano y el capital financiero transnacional, la "farandulización" del mundo político y la conversión del balcón de la Casa Rosada en el escenario de un literal simulacro (con Madonna interpretando a Evita para la película de Alan Parker), fueron emergiendo numerosos análisis que, a la luz de esos tiempos, supieron enfatizar la relación entre Eva Perón y la cultura de masas. Aquella "moda" se tradujo en el film Evita (1996) de Parker y en la película Eva Perón de Juan Carlos Desanzo (1996), así como también en la publicación de novelas muy promocionadas como La pasión según Eva de Abel Posse (1994) y Santa Evita de Tomás Eloy Martínez (1995). A la vez, ese impulso se proyectó hacia la década siguiente, motivo por el cual libros de ensayos como los firmados por Beatriz Sarlo (2003), Claudia Soria (2005), Susana Rosano (2006), Alejandro Susti González (2007) o el volumen coordinado por Soria y María Cristina Pons (2005), pueden considerarse como herederos de los años menemistas en tanto hacen foco en la búsqueda del origen peronista y el auge de la cultura de masas.

Dentro de este marco, también puede identificarse un importante número de autores pertenecientes a la narrativa argentina contemporánea que han configurado a Eva Perón en consonancia con las diversas líneas temáticas y estéticas desarrolladas durante la segunda mitad del siglo pasado. Pero a la vez, en los primeros años del presente siglo algunas obras han comenzado a abrirse paso hacia ciertas configuraciones que no se atienen a los discursos cristalizados, tales como el hagiográfico del peronismo histórico ${ }^{3}$ y la "leyenda negra"

2 En Los cuerpos de Eva. Anatomía del deseo femenino (2005), Claudia Soria daba cuenta de esta semejanza entre Rosas y Eva Perón, sobre cuyas figuras "se presentan dos escrituras como viables: la del amor o la del odio" (p. 19). Además, destacaba la seducción que la barbarie ejerce en nuestra literatura desde sus orígenes: "Rosas y Eva son figuras caudillas, ajenas a la tradición literaria, pero motivadoras e impulsoras de la escritura" (p. 20).

3 Citamos a modo de ejemplo un fragmento del texto laudatorio de Nicolás Olivari publicado en el 
forjada por los anti-peronistas ${ }^{4}$. Las obras de Juan Martini que nos disponemos analizar se ubican en esta línea.

Cine es la tríada de novelas protagonizadas por Sivori, realizador independiente que pasada la mitad de su vida se propone realizar una trilogía fílmica sobre Eva Perón. Al mismo tiempo y tal como lo ha manifestado el propio Martini ${ }^{5}$, Cine puede pensarse como una sola novela cuyas partes van escalonando la radicalización experimentada por Evita entre 1945 y 1952, es decir, durante el breve lapso de tiempo que comprende su entera actuación política. En este sentido Sivori, alter ego de Martini, se muestra obsesionado por indagar cómo, en tan solo siete años, Eva pudo convertirse en el mito más potente de la historia argentina. A partir de esta obsesión, las novelas (que también son las tribulaciones que la escritura de los guiones despierta en un vecino de barrio Palermo subsumido en su vida nimia) muestran a una Eva revivificada, en permanente movimiento y mutación.

Sylvia Saítta se preguntaba al final de una nota aparecida en el diario La Nación en julio de 2002, luego de repasar la parábola que había llevado a Eva a convertirse "de actriz a personaje literario", si la potencialidad política de Eva Perón había sido finalmente conjurada ${ }^{6}$. De acuerdo con su diagnóstico, la moda de mediados de los '90 había legado

suplemento-homenaje a Eva Perón del diario La Prensa, el 24 de agosto de 1952. En esas líneas, Olivari recordaba una vez que debió esperar algunas horas para ser atendido por "Ella" en su Fundación, siendo testigo del amor entre Evita "y sus pobres": "Y yo me dije, en un tácito arrodillamiento de poeta, obligado a reconocer la presencia de ese milagro que se conjugaba delante de mi temblorosa emoción, yo me dije, mientras sentía cómo se removía en mi alma la oscurecida fe de mis antepasados, que solo Dios y Ella podían producir ese milagro" (p. 3).

4 The Woman with the Whip ("la mujer del látigo") es una temprana biografía difamatoria aparecida en Inglaterra y Estados Unidos hacia 1952. En Argentina fue publicada en 1955, una vez derrocado Perón. Fue escrita por Mary Mein, periodista y novelista angloargentina que nació en 1903 y vivió en nuestro país hasta finales de la década del '30. La obra fue publicada originalmente en Inglaterra y en los Estados Unidos y contiene todas las acusaciones que el antiperonismo sostendría desde entonces y hasta nuestros días. De tal modo, Eva es una bastarda resentida y advenediza que no escatima en bajezas, prepotencias y todo tipo de subterfugios para mitigar su insaciable sed de venganza. De modo complementario, Perón resulta configurado como un pelele, motivo por el cual sus respectivos roles se invierten: ella es el hombre y él, la mujer (cfr. Rosano, 2006, pp. 118-124).

5 Hacemos alusión a cierto pasaje de la entrevista que le hizo Patricio Zunini para el blog de Eterna Cadencia, publicada en el año 2010 con el título "El proyecto de Evita era más socialista que peronista". Nacido en Rosario en 1944, Martini es uno de los narradores más importantes de su generación. A lo largo de cuatro décadas, ha publicado diecisiete títulos entre novelas y cuentos. En 1964 co-fundó Setecientosmonos, una importante revista literaria cuya vida se extendió hasta 1968. Entre 1975 y 1984 permaneció exiliado en Barcelona, donde se desempeñó como editor, tarea que continuó desarrollando después de su retorno a la Argentina. En la actualidad, su principal actividad es la coordinación de talleres literarios.

6 La cita a la que hacemos referencia es la siguiente: "Voz conciliada, cuerpo mudo, ícono de la cultura massmediática, la potencialidad política de Eva Perón, ¿ha sido finalmente conjurada?” (Saítta, 2002). En relación con el artículo, Saítta apelaba a un proverbial poder de síntesis para repasar las configuraciones de Eva en obras de Jorge Luis Borges ("El simulacro"), David Viñas ("La señora muerta"), Mario Szichman (A las 20:25 la Señora entró en la inmortalidad), Rodolfo Walsh ("Esa mujer”), Leónidas Lamborghini (Las patas en las fuentes, "Eva Perón en la hoguera”), Copi (Eva Perón), Néstor Perlongher ("Evita vive", "El cadáver" "El cadáver de LA NACIÓN"), Adolfo Bioy Casares (Dormir al sol), Tomás Eloy Martínez (La novela de Perón, Santa Evita), Ricardo Piglia (La ciudad ausente), Rodrigo Fresán ("El único privilegiado") y Abel Posse (La pasión según Eva).

Doi: https://doi.org/10.15517/rfl.v45i2.39099 / URL: https://revistas.ucr.ac.cr/index.php/filyling/index 
un puñado de obras que cerraron el ciclo de la Evita que vive para obturar su regreso. Saítta mencionaba las dos novelas más representativas del periodo, La pasión según Eva de Posse y Santa Evita de Eloy Martínez, para observar la complementariedad de sus respectivas operaciones. En primer término, la Eva configurada por Posse dejaba de "ser política para convertirse en la voz de ultratumba de una fiel enamorada, en un final de literatura fantástica"7 (2002, párr. 9); en segundo término, la Evita de Martínez encontraba "su destino como heroína literaria del realismo mágico latinoamericano", convirtiéndose en un "pasivo cadáver manipulado [...] cuya única acción es multiplicar mágicamente las velas y las flores en los diversos lugares donde los militares intentan esconderla" (Saítta, 2002, párr. 9). Eva, afirmaba Saítta, subsistía como un objeto inerte (una muñeca, siguiendo la serie que va desde Jorge Luis Borges con la obra "El simulacro" de 1960/1998a, hasta César Aira y su texto "Las dos muñecas", 1998) y su "potencialidad política" quedaba clausurada.

En 2003, un año después de la publicación del artículo referido, una novela de Daniel Herrendorf titulada Evita, la loca de la casa parecía querer conjurar definitivamente su proyección política. Este tercer -y hasta el momento último- título de ficción publicado por Herrendorf constituye, en efecto, un sólido eslabón en la cadena de textos que a lo largo de las últimas décadas configuraron a Eva desde la leyenda negra y el simulacro, y para referirnos a su contenido, podríamos usar los mismos términos que Inés De Mendonça y Juan Pablo Lafosse emplearon para aludir a la obra Eva Perón de Copi:

si (él) decide dar vida a la difunta no lo hace para apuntalar el mito ni para modificar su estructura, sino para enfrentarlo violentamente atacando cada uno de sus principios. O mejor dicho, hiperbolizando cada uno de los antivalores del anti-mito que se va construyendo como contracara y respuesta del discurso justicialista (2006, párr. 23).

Teniendo en cuenta estos antecedentes, en el presente trabajo intentaremos demostrar que la figura de Evita como símbolo de las reivindicaciones populares fue encontrando hacia finales de la década pasada un nuevo puerto en las obras de Martini. Decíamos líneas arriba que Cine se nos presenta como una gran historia que, a su vez, contiene el errático proyecto de una trilogía fílmica desarrollado por Sivori. En ella, el director pretende indagar las posibilidades de tratamiento de la figura de Eva Perón alrededor de tres momentos fundamentales de su vida. Siguiendo esta disposición, dedicaremos sendos apartados al análisis de las novelas.

\section{Cine: otra mujer}

La saga consta de tres títulos publicados por la editorial Eterna Cadencia en años sucesivos: Cine (2009), Cine II. Europa, 1947 (2010) y Cine III. La inmortalidad (2011). Los volúmenes -que suman un total de quinientas cuarenta páginas- se muestran como variaciones sobre el mismo leitmotiv, motivo por el cual decidimos emplazar nuestro eje de lectura entre los cambios y las permanencias que tensionan la conformación y el desarrollo de la subjetividad política de Eva Perón. Una primera constante a señalar es su voluntad absolutamente consciente de convertirse en mito. Esa voluntad se pone de manifiesto a través de la voz narradora de Sivori y de la propia Eva, dado que las películas -siguiendo los preceptos

7 "De actriz a personaje literario", disponible en www.lanacion.com.ar/221755-de-actriz-a-personajeliterario.

Doi: https://doi.org/10.15517/rfl.v45i2.39099 / URL: https://revistas.ucr.ac.cr/index.php/filyling/index 
estéticos del realizador ${ }^{8}$ - consisten en diferentes diálogos mantenidos con Rita Molina, Lillian Lagomarsino y Emma Nicolini, ocasionales interlocutoras de la protagonista.

En el guión de la primera parte, cuyo título es 17 de octubre, una Eva de 26 años conversa con su amiga y colega Rita Molina en el departamento donde moraba la entonces actriz y futura primera dama, entre las cinco y las siete de la tarde de aquella histórica jornada. Desde las primeras líneas de ese diálogo cuyo telón de fondo es "una sola imagen de la ciudad: hombres y mujeres mojándose los pies en una fuente de la Plaza de Mayo" (Martini, 2009, p. 178)9 , le exige a Molina que nunca más la llame "Cholita" (p. 19). Para esta Eva configurada por Sivori-Martini, la necesidad de "cambiar su nombre" corre a la par de sus posibilidades de "cambiar la historia del país" (p. 160). Para ella, lo personal es político; por este motivo, en esa tórrida jornada que abrirá las puertas a lo que vendrá, le advierte a su colega que está decidida a convertirse en "otra mujer" (p. 107). A partir de allí, dejará el cine, el teatro y la radio para comenzar a forjar su propia leyenda. Por otra parte, si bien muestra algunos reparos contra Perón, reconoce que sin él no podrá hacer cumplir su voluntad y exhibe ribetes proféticos al afirmar que no tendrá hijos, que morirá joven (p. 121) y que una vez muerta "entrará en la inmortalidad” (p. 161).

La novela plantea, al mismo tiempo, que la ruptura con su pasado artístico es también una forma de continuarlo; no porque el balcón presidencial se convierta en un simple sucedáneo del escenario ${ }^{10}$, sino porque el ciclo Grandes mujeres de todos los tiempos que Eva protagonizó en Radio Belgrano se erige como un presagio de su propio destino ${ }^{11}$. En este sentido, la obra de Martini nos recuerda las reflexiones de Susana Rosano en torno a la "hibridación" entre las "lógicas de representación" del Estado y de la industria cultural que el peronismo inauguró y que posibilitó el ingreso de Eva en la dimensión "legendaria" del "imaginario popular" (2006, p. 21). Pero más allá de esta hibridación, el guión de Sivori pretende postular que aquello que

8 Sivori es un realizador independiente cuyas películas se caracterizan por ser "historias mínimas". No resulta casual nuestra referencia al título del film con el que Carlos Sorín resurgió en la cinematografía argentina a principios de la década pasada. En sintonía con películas como Historias mínimas (2002) o Bombón, el perro (2004), los largometrajes dirigidos por Sivori -comentados en Cine II- traman anécdotas sencillas sin desdeñar la tensión dramática. Además, Sorín aparece como personaje en la segunda parte de la saga, cuando Sivori acude a él en busca de consejo.

9 A tono con la invasión (Avellaneda, 1983) que esa otredad popular representó para los habitantes de la Capital, el narrador informa que en el guión de 17 de octubre: "La ciudad que se ve, la ciudad que se trasluce en la opacidad de un interior, es, por primera vez, la ciudad del otro" (Martini, 2009, p. 178).

10 Adoptamos la expresión de Comediantes y mártires. Ensayo contra los mitos, libro en el que Juan José Sebreli afirmaba que: "las estrellas comparten con los dioses del Olimpo vivir alternativamente el mundo real y el mundo imaginario. Gardel se limitó al mundo del espectáculo; Evita llevó este último a la política; el único espectáculo por el que triunfó fue en el balcón frente a la plaza, sucedáneo político del escenario teatral" (2008, p. 37). Como vemos, la lectura de Sebreli busca constatar la consumación de un simulacro perfecto: de la mano de Eva, el "mundo de la política" fue reemplazado por el "mundo del espectáculo" y el balcón de la Casa Rosada pasó a ser el escenario para su actuación consagratoria.

11 Según la lista presentada por la novela, en ese ciclo (que se llamó Heroínas de la historia y fue transmitido con algunas interrupciones entre octubre de 1943 y septiembre de 1945) Eva encarnó los roles de: Isabel I de Inglaterra, Sara Bernhardt, Madame Chiang Kai-shek, Lady Hamilton, Isadora Duncan, Ana de Austria, Eleonora Duse, Eugenia de Montijo, Carlota de México y Catalina la Grande (Martini, 2009, p. 107). En este listado brillan por su ausencia "heroínas" más cercanas como la paraguaya Madame Lynch, mujer del mariscal Francisco Solano López (quien fue, además, el personaje que inauguró la serie), o Margarita Weil de Paz, sobrina y esposa del general Paz.

Doi: https://doi.org/10.15517/rfl.v45i2.39099 / URL: https://revistas.ucr.ac.cr/index.php/filyling/index 
el mundo artístico sembró en Eva fue la posibilidad de auto-inventarse y modificar la realidad abrevando en su propia voluntad.

En un artículo titulado "La voz de Eva Perón: ¿qué dice una mujer cuando habla", Claudia Soria hacía una apreciación similar en relación con la influencia fundamental ejercida por la radio en la Eva niña. Partiendo de un análisis que reconocía la superposición entre la figura histórica y el "ícono" o "artefacto cultural" en el que devino, Soria se detenía en algunos pasajes de La pasión según Eva para observar cómo, durante su infancia pueblerina, Doña Juana Duarte y sus hijos realizaban las actividades diarias alrededor de la radio:

En el contexto de un padre ausente (muerto), la radio se transforma en 'la voz' a través de la cual las noticias del mundo (la civilización masculina) penetran en el hogar materno primero en Los Toldos, y luego en Junín. (...) Es decir, la radio, la voz del padre, le permite a Eva soñar con un mundo social que le está vedado por ser hija ilegítima y, por ello, sin padre, sin clase y sin dinero. En cierto sentido, la radio alimenta la imaginación de la niña y le permite fantasear con otro espacio más allá del pueblo, simbólicamente bendecido por la voz del padre (Pons y Soria, 2005, p. 148).

Volviendo a la novela de Martini, frente a esta Eva Perón configurada alrededor de su férrea voluntad y su claro sentido de trascendencia, Sivori y su entorno vienen a generar un efecto de contraste. En tal sentido, si bien la obra provee datos que invitan a concebir a Sivori como un sobreviviente de la restauración conservadora que siguió a la revolución derrotada $^{12}$, la voluntad no remite aquí a la militancia de la década del "70 sino a una Eva que, de haber sobrevivido, hubiese sido efectivamente "montonera". Sivori, por el contrario, atraviesa una vida trivial y "en el fondo todo le parece un poco inútil, un poco ocioso, y un poco imbécil" (2009, p. 25). Dentro de esta atmósfera que la voz narradora describe como "una suerte de zozobra en el alma, y ganas de llorar" (2009, p. 27), su existencia se trastoca ante la llegada de Pina Bosch, una vecina a quien espía y con quien comenzará a desarrollar un peculiar vínculo amistoso. Para no torcer nuestro objetivo, evitaremos ahondar en este plano de las novelas del cual participan también otras mujeres como Carola Holmes y Simone Borghini. Sin embargo, queremos señalar dos aspectos fundamentales que hacen a la conformación subjetiva de este conjunto de personajes. Por un lado, destacamos la conciencia que Sivori tiene sobre la época escéptica que le toca vivir y cómo el clima del momento puede llegar a penetrar en su obra. De este modo:

Él se pregunta si la película que ha imaginado sobre Eva Duarte tendrá las marcas de una época. No las marcas de hace más de sesenta años, que es cuando transcurrirá la película, sino las marcas de hoy. Es decir, se pregunta Sivori, si su película desplegará en noventa o en ciento veinte minutos una figura de Eva Duarte reinterpretada por otra época, no la suya sino esta, este tiempo que transcurre en la política de todo el mundo con la brutal indiferencia que rige los primeros años del siglo $\mathrm{XXI}^{13}$ (2009, p. 33).

12 Lacruz y De María son dos viejos amigos con los que Sivori se reúne periódicamente a cenar. El narrador los caracteriza en unas pocas líneas de la siguiente manera: "Los tres creyeron en alguna revolución, cuando había revoluciones. Los tres les deben a los años 70 las ideas más bellas y las más débiles. Hoy creen, sin embargo, que el cambio más grande que vivieron fue la caída del muro de Berlín. Nadie entiende todavía, dice De María, que el fin del capitalismo empezó en noviembre de 1989" (Martini, 2009, p. 96).

13 Dicho clima de indiferencia generalizada se cifra en la expresión "no sabe porqué" (Martini, 2009, p. 131) que la voz narradora (cuya entonación es a la vez omnisciente y distanciada) emplea reiteradamente para referirse a Sivori y su percepción del entorno. En otros términos, el protagonista se muestra extrañado frente a lo cotidiano, motivo por el cual permanece suspendido en una suerte de deriva existencial. 
Por otra parte, es importante observar el hecho de que Sivori y Bosch comparten, sin ser peronistas, una misma fascinación por Evita. A Sivori lo cautiva esa "mezcla de clarividencia política y de obstinación, de resentimiento y de grandeza, de desamparo y de coraje" (2009, p. 42) que detecta en su figura; y cuando en uno de sus primeros encuentros le cuenta a Pina (traductora del alemán, cinéfila y voraz lectora) sobre el guión que lo tiene ocupado, "ella le dice que ella, que no fue ni es peronista, ha quedado siempre fascinada con la figura de Evita" (2009, pp. 111-112). Dada esta situación, Sivori no se muestra atribulado ante lo que Eva pueda representar en términos políticos, sociales o culturales, sino en relación a cómo representarla con la mayor fidelidad posible dentro de su película. Por eso, "el problema de Sivori es que su guión no le gusta” (2009, p. 160): "A Sivori no le gusta el guión porque le parece que no aprehende, que no expresa, que no enuncia lo que él pretendía que aprehendiese, expresara o enunciase: la voluntad consciente de Eva de convertirse en un mito" (2009, p. 170).

Con esta sensación de insatisfacción se cierra el primer volumen de Cine. Mientras tanto, se va abriendo paso en Sivori la idea de una trilogía que podría llamarse La pasión, y Florencia, hija de su amigo y productor Agustín "Dippy” Dillon, le pide ser su asistente de dirección.

\section{Cine II. Europa, 1947: viaje, retorno y conversión}

Sobre el final del diálogo con Rita Molina, la "Eva vate" configurada por SivoriMartini anticipaba el viaje que la llevó por Europa dos años más tarde. Según sus palabras, con ese periplo iba a enseñar a "los ricos [...] que nada está prohibido para nadie" (2009, p. 105), y henchida de amor y de odio agregaba:

A mí no me aturden los berridos de las criaturas y el llanto de las madres que los ven morir de hambre. Yo no les tengo asco al sudor y a la mugre de los pobres. Yo me voy a ensuciar las manos con mierda si hace falta, y me las voy a secar con las toallas de seda de los oligarcas (Martini, 2009, p. 105).

En Cine II. Europa, 1947 (Martini, 2010), Sivori se dispone a escribir otro diálogo entre una Eva convertida a los veintiocho años en “Doña María Eva Duarte de Perón” (p. 10) y Lillian Lagomarsino, su acompañante en la gira que a lo largo de setenta y ocho días la llevó por España, Italia, Portugal, Francia y Suiza. La conversación tendría lugar en Rapallo, comuna costera de la Provincia de Génova donde Eva y su comitiva se detuvieron a descansar promediando el viaje. Allí las palabras de la primera dama hacen confluir, en clave confesional, elementos que apuntan tanto al cambio como a la permanencia de una subjetividad política proyectada hacia el devenir mítico. En tal sentido, a través de la visión que Sivori sostiene en torno a Eva, la voz narradora enfatiza su voluntad de "pasar a la historia" (2010, p. 54) y explicita una segunda constante que, aunque presente en la novela anterior, aún no había sido formalizada:

Sivori, que no es ni ha sido peronista, tiene sin embargo una fuerte empatía por Eva, un reconocimiento que se sostiene en la voluntad de esa mujer de trabajar para los pobres, y en su deseo de pasar a la historia exactamente por eso: por dar la vida trabajando incansablemente por la dignidad de los humildes (Martini, 2010, p. 10).

Esto se ve reflejado en el guión cuando Eva le cuenta a Lagomarsino que en la Gira proselitista que hizo junto a Perón en diciembre de 1945, se dio cuenta de que "estaba dispuesta a morir por esa gente" (2010, p. 92). Por otra parte, la Eva humanizada y "en movimiento" configurada por la trilogía fílmica empieza a dar muestras de un sentimiento hasta entonces inédito: el miedo. En sus permanentes cruces intertextuales, la novela remite a testimonios ofrecidos posteriormente por Lagomarsino para tomar nota de los "terrores 
nocturnos" y las pesadillas "que la acompañaron a lo largo de esos dos meses y medio" 14 (2010, p. 40). La Eva de esta segunda película sabe que sus diferencias con Perón serán cada vez más grandes, que le quedan solo cinco años para cumplir su voluntad y que "lo que no haga [...] hasta 1952 no lo va a hacer nadie: Por eso quiero que no me olviden. Para que después no puedan borrar de un plumazo mi obra" (2010, p. 104).

Florencia Dillon va tomando la posta de Sivori. Como asistente de dirección, eleva una serie de informes que proyectan el contenido del diálogo mantenido en las playas de Italia hacia lo sucedido a posteriori de esa gira que le permitió a Eva convertirse, para despecho de "los oligarcas y los gorilas", en "una reina plebeya" (2010, p. 138). En este sentido, a su regreso "Doña María Eva Duarte de Perón" pasa a ser, de inmediato y para siempre, "Evita": abandona los vestidos presidenciales, las joyas, los peinados y los perfumes importados, y uniformada con un traje sastre y un rodete inamovibles, impulsará la mayor obra social jamás vista en la Argentina.

De acuerdo con Zulma Sacca (2003), el "edificio discursivo" alrededor de la vida de Eva se fue erigiendo sobre tres peripecias centrales: el viaje, la enfermedad y la resurrección. Cine II aborda la primera de estas peripecias. Como el héroe mítico, Eva se aleja de su "mundo ordinario" y, luego de sortear una serie de pruebas con enemigos y aliados, regresa a casa con un "elixir" que emplea para ayudar a los que habitan el mundo ordinario. Siguiendo el esquema tripartito sugerido por Joseph Campbell (1972), su caso presenta el proceso de separación, iniciación y retorno de todo héroe mítico. Ahora bien: como este retorno resulta imprescindible para que la peripecia del héroe redentor se realice, resulta siempre negado por quienes ven en Eva un ejemplo paradigmático del simulacro populista. Juan José Sebreli señalaba, a modo de ejemplo, que

Evita vestía ropa de Christian Dior y se adornaba con alhajas de Van Cleff. Ella decía que le había sacado las joyas a la oligarquía para dárselas al pueblo, que las heredaría. Lejos estaba de suponer que al fin serían exhibidas en una feria para su remate ${ }^{15}(2008$, p. 34).

Para este tipo de lecturas, el viaje del "héroe" no tiene retorno; así, mitos como el de Eva Perón pueden equipararse a la historia de Droctulft, el bárbaro guerrero que murió defendiendo a Roma, según el relato que Borges dijo haber hallado en un libro de Croce ("Historia del guerrero y la cautiva", El Aleph, 1998b). Sin embargo, si nos atenemos a ese testimonio político de Eva Perón que es Mi mensaje (2012), el recorrido planteado allí es el de ascenso y posterior retorno al punto de origen, motivo por el cual su iniciación habría implicado, fundamentalmente, no dejarse tentar por las alturas.

Volviendo a la novela, al reparar en esa conversión Florencia experimenta la fascinación que antes había embargado a Sivori. Mientras tanto, el director extrema su interpretación sobre

14 En el octavo capítulo de la novela, Florencia Dillon intenta responder “¿quién era Lillian?”. Según su informe, en 1947 Lagomarsino tenía treintaiséis años y era la esposa de Ricardo Guardo, el primer presidente de la Cámara de Diputados del gobierno de Perón. Aunque tenía un hijo de apenas un año, ella aceptó acompañar a Eva ante la insistencia de Perón, ya que "sabía muy bien francés y tenía una esmerada educación, cualidades que le serían útiles a Eva” (Martini, 2010, p. 75). Sin embargo, Florencia recurre a un reportaje a Lagomarsino realizado por Magdalena Ruíz Guiñazú (publicado en Página/12 en 1998) y a un libro de memorias aparecido dos años antes (Y ahora ... hablo yo) para afirmar que "sobre todo decidió acompañarla porque veía en ella a una chica solitaria, frágil y atemorizada." (Martini, 2010, p. 75).

15 Haciendo un particular uso de la elipsis, Sebreli evita mencionar que esas joyas fueron secuestradas y subastadas por quienes orquestaron el golpe de 1955. 
la contigüidad de las trayectorias artística y política de Eva, afirmando ahora que la "escritura de un nombre" es "una obra de arte" (Martini, 2010, p. 11) y "que la reescritura de un nombre y la reconstrucción del propio mito en solo siete años es uno de los géneros y una de las obras maestras propias del siglo XX"16 (Martini, 2010, p. 12).

En lo que respecta a Sivori y su contexto, Dippy Dillon, su amigo y paciente productor ejecutivo, muere a causa de una sobredosis de cocaína. Por su parte Pina Bosch, deprimida y anoréxica, intenta suicidarse en una habitación de hotel pero sobrevive y acude a Sivori para que la acompañe en su recuperación. Asimismo, va apareciendo en escena Juana Herralde, madre de Florencia, quien ocupará un rol destacado en la tercera parte de la saga. Sivori comienza además a pergeñar un documental sobre los monumentos que observa en sus andanzas por los espacios urbanos y recibe una invitación de Carola Holmes para viajar a Nueva York. Dada su permanente dispersión, el proyecto fílmico sobre Eva Perón quedará sostenido por el entusiasmo de la joven Dillon, quien será la encargada de proveer la clave para ingresar en la siguiente novela:

\begin{abstract}
Yo sé que ustedes recogerán mi nombre y lo llevarán como bandera a la victoria, dice Eva cuando ya sabe que su muerte está muy cerca, escribe Florencia Dillon: Esta frase, Sivori, tiene que estar, porque si yo entiendo tu película esta frase es Eva en estado puro, material... (Martini, 2010, p. 175).
\end{abstract}

\title{
4. Cine III. La inmortalidad: soy leyenda
}

Si Cine II se centraba sobre la peripecia del viaje, Cine III (2011) lo hace en relación con la enfermedad, la muerte y la resurrección de Eva Perón. Ha pasado un año desde el final de la novela anterior y en su viaje a Nueva York, Sivori no ha podido concretar avances significativos en el rol de productor que, muerto Dippy, sufridamente asumió. Simone Borghini, la novia de Carola Holmes (quien había tenido una relación con Pina Bosch cuyo fin motivó su intento de suicidio en Cine II), intenta contactarlo con productoras independientes como la danesa Zentropa, pero nada se define.

Desde Buenos Aires, Florencia Dillon interpela a Sivori para decirle que cada día cree más en Eva y rogarle que no la "abandonen" (2011, p. 16). A medida que elaboraba los informes para la película, la asistente de producción fue identificándose con la Evita "fanática" cuyo testamento político es Mi mensaje (2012). Florencia compara a Evita con Juana de Arco (protagonista, además, de un clásico film de Carl Dreyer) y transcribe largos pasajes del "mensaje" legado por esa mujer que decidió arder en su propio fuego. Estas transcripciones ocupan varias páginas de la novela y en ellas puede leerse buena parte de la introducción ("Mi mensaje") y el sexto apartado dedicado a "Los fanáticos". De acuerdo con la interpretación de Florencia, Mi mensaje "es un tiro por elevación”: "Ella se está muriendo, Sivori. No puede

16 Añadimos que esta "reescritura del nombre" en el caso de Evita se presenta de manera literal, ya que a instancias del matrimonio contraído con Perón el 22 de octubre de 1945 en la localidad de Junín, su partida de nacimiento fue adulterada para que figurase como hija legítima de Juan Duarte. De esa manera se intentó borrar la mácula que pesaba sobre "María Eva Ibarguren" por ser una "hija adulterina" (Pigna, 2012, pp. 15-18). A la vez, en el cruce entre lo personal y lo político que marca el camino de Eva, aquel episodio se proyectará hacia la sanción de una ley que el peronismo impulsó dos años después de su muerte y que eliminó discriminaciones infamantes como hijos "adulterinos", "sacrílegos", "mánceres" o "naturales", aunque mantuvo la diferencia entre hijos "legítimos" e "ilegítimos". 
prescindir de Perón. Pero le está hablando al pueblo: le está pidiendo a la gente que no permita que Perón los traicione, o que no traicione el legado que ella les deja...” (Martini, 2011, p. 27).

A partir de esta lectura, la tercera parte de La pasión presenta a una Eva que se ha convertido en "estorbo político" para Perón (p. 39). Esa fue, asume Florencia, la conclusión a la que Evita llegó en 1951 después del Cabildo Abierto y las presiones ante las cuales Perón cedió para que ella renunciase a la candidatura vicepresidencial propuesta por la CGT. En tales circunstancias, Perón le ha soltado la mano y Eva decide pasar unos días en El Tropezón, un refugio de El Tigre, para reflexionar sobre la dirección que tendrán sus últimos pasos. El diálogo presentado por el tercer guión resulta, entonces, el que mantienen allí Emma Nicolini, hija de diecisiete años del ministro Oscar Nicolini, y una Eva de 32 años que, convertida en "Evita", moraba en territorios legendarios ${ }^{17}$.

Por otra parte, su tono se aproxima llamativamente a aquel forjado por la literatura antiperonista y que Copi supo parodiar como ningún otro autor. En un cuasi monólogo, la protagonista se despacha contra Perón sin ahorrar epítetos ("Perón es un boludo. Un cobarde. Un milico." -2011, p. 48-), asegura que nunca nadie acumuló tanto poder para luego dilapidarlo y le pregunta a Nicolini: “¿Qué duda cabe de que Perón y yo terminamos representando cosas distintas?" (2011, p. 50).

Al remarcar la radicalización de Evita y sus irreconciliables diferencias con Perón, la trilogía de Sivori-Martini permite ampliar las correspondencias entre el desencuentro del líder y John William Cooke en los años '60 y las desavenencias entre Perón y la Tendencia Revolucionaria durante la década siguiente; pero a la vez, Eva encarna otra "cosa diferente" en relación con Perón: el sentido sacrificial de su obra, que fue elevándola hacia la dimensión inaprehensible de la leyenda. Mientras la figura de Perón siempre requirió que otros muriesen por él ("la vida por Perón", vociferaba la propia Eva), la figura de Evita simboliza al mártir que muere por los otros. De tal manera, el final de La pasión señala que su camino hacia la muerte sacrificial acabó inmortalizándola, al tiempo que abolió todo atisbo de simulacro para ubicarla en un más allá respecto de los usos políticos sobre su figura. Que su nombre haya sido -siguiendo la tradición bíblica- el de la primera mujer, que su muerte haya ocurrido -al igual que Jesús- a los treintaitrés años de edad, y que haya sido producto de un cáncer cervical que le impidió procrear a esta "madre de los descamisados", son hechos que indudablemente colaboraron para que su voluntad de convertirse en leyenda se cumpliera con creces.

Pero además, las inserciones de la voz de Eva Perón en la obra de Martini incluyen un fragmento del discurso que ofreció el 17 de octubre de 1951. Evita se encontraba visiblemente débil a causa de su enfermedad, pero acudió para agradecer a los trabajadores de la CGT por el homenaje que le brindaban y por haberse "jugado" por Perón durante el intento de golpe sucedido el 28 de septiembre. Advirtió entonces que "no ha pasado el peligro [...] porque los

17 En las líneas que dan cierre a Eva Perón, Otello Borroni y Roberto Vacca remarcan la condición de mito viviente que Evita alcanzó en sus últimos años: "Eva Perón, a partir de 1949, irrumpe en el escenario político argentino ya no como figura, sino como mito. Por lo tanto su desarrollo posterior solo produciría en el régimen peronista -y en ella misma- un desborde incontrolado. Su nombre, su figura, su palabra, estaban insertados profundamente en el sentimiento popular. El proceso de su enfermedad, La razón de mi vida, su proclamación como candidata a la vicepresidencia de la República, su posterior 'renunciamiento' ante presiones militares, la adquisición de armamentos destinados a la formación de milicias obreras para apoyar al gobierno peronista, su campaña proselitista desde su propio lecho de moribunda y las instancias finales de su vida aquilataron aún más ese sentimiento popular” (1970, p. 111). 
enemigos trabajan en la sombra de la traición, y a veces se esconden detrás de una sonrisa o de una mano tendida" (Martini, 2011, p. 50), y arrojó para la posteridad aquella expresión que citamos en boca de Florencia Dillon al concluir el apartado anterior:

Mi gloria es y será siempre el escudo de Perón y la bandera de mi pueblo y aunque deje en el camino jirones de mi vida, yo sé que ustedes recogerán mi nombre y lo llevarán como bandera a la victoria (Martini, 2011, p. 50).

Estas palabras se corresponden a todas luces con quien ya habitaba el mito y constituyen, junto con Mi mensaje, el fiel testimonio de la radicalización de Eva ${ }^{18}$.

A un mismo tiempo y a la par, ese discurso de Eva fue la primera transmisión televisiva realizada en Argentina, motivo por el cual sus palabras vienen a representar el máximo grado de "hibridación" entre las "lógicas de representación" del Estado y la industria cultural. De acuerdo con el planteamiento de Sivori-Martini, se trata de una confluencia de mundos que Eva siempre cultivó y que -como hemos señalado- posibilitó su temprano ingreso en la dimensión legendaria del imaginario popular ${ }^{19}$. Dados estos motivos, en la tercera y última parte de la saga la voz narradora postulará que, hacia el final de su vida, "Eva ya no es Eva. Y Evita, el nombre que ella misma eligió, ahora es el nombre de su leyenda" (2011, p. 149): "ella instaló su imagen en lo más sagrado de una pasión masiva: la inmortalidad" (2011, p. 52).

En lo que respecta a Sivori, él comienza a sospechar que su proyecto tal vez despertó "el temor de los productores", quienes frente a la composición de una Evita fanatizada y enfrentada con Perón, pudieron haber pensado "que se estaban metiendo en la realización de una película ultraperonista, o, lo que sería peor, de una película gorila” (2011, p. 85). Por otra parte, los capítulos de Cine III llevan por título los nombres de los personajes de la novela. En uno de ellos, Juana Herralde, ex mujer del malogrado Dippy y madre de Florencia, toma la palabra. Confiesa entonces la culpa que le despierta no haber criado a su hija como deseaba (2011, p. 98) y le dice a Sivori que la entusiasma verla participar en sus películas. La voz narradora informa, a su vez, que Juana es descendiente de una familia "gorila" que abrazó la causa peronista integrando la JP y Montoneros y que, desde un inicio, le gustó la idea de $L a$ pasión porque ella "es peronista": "Pero, antes que peronista, comparte con Sivori el respeto por Eva. Eva fue revolucionaria. Y este país hubiera sido otro si Eva no hubiese muerto tan pero tan joven" (Martini, 2011, p. 104). Con el ingreso de Juana (homónima, además, de la madre de Eva) se amplía la unánime empatía entre los personajes de la novela y la figura de Evita; asimismo, aporta un nuevo pliegue a la identificación entre Florencia y "la abanderada de los humildes" y marca una genealogía que permite, a través del cine y de la literatura (hacedores principales de Eva como "artefacto"), trasvasar a las nuevas generaciones su obra, su mito y su mensaje.

18 La trascendencia de Evita hizo que el imaginario popular le atribuyera la expresión "volveré y seré millones". Esas fueron, en verdad, las últimas palabras pronunciadas por el líder aymara Túpac Catari antes de ser descuartizado por orden del Imperio Español, en 1781. En 1962, como homenaje al cumplirse una década de su muerte, José María Castiñeira de Dios compuso el poema "Eva Perón". Evita tomaba allí la palabra y "desde el Cielo" lanzaba esa frase, atinado octosílabo que vino a formar un tándem perfecto con "yo sé que ustedes recogerán mi nombre y lo llevarán como bandera a la victoria”, sentencia que Eva efectivamente legó.

19 En sintonía con nuestra lectura, sobre el final del artículo "La voz de Eva Perón: ¿qué dice una mujer cuando habla?", Claudia Soria recordaba la "famosa frase" pronunciada por Eva en su discurso del 17 de octubre de 1951 y pasaba a señalar: "En esa voz y en sus ecos, la moribunda Eva ofrece su propio cuerpo femenino como relevo, como puente, para que otros (las masas) usen su nombre y eleven su grito de guerra revolucionario" (Pons y Soria, 2005, p. 156). 


\section{El eterno retorno del mito}

Una sentencia de Dippy viene a redimensionar los cambios y las permanencias que traman la trilogía de Sivori-Martini. En las últimas páginas de Cine, la voz narradora menciona "una idea central en el pensamiento de Dippy Dillon": "La historia de este país es la historia de los proyectos olvidados" (2009, p. 170). Promediando Cine II y frente a las tribulaciones de Sivori, la expresión se repite cuando esa misma voz advierte que "es muy probable que el proyecto ingrese en el hangar de los proyectos olvidados" (2010, p. 70). La reiteración de esa idea viene a generar una homologación ya no entre las novelas de Martini y las películas de Sivori, sino entre estas y el proyecto político de Eva Perón. Dada esta equiparación, en un momento de la segunda parte leemos:

de pronto, Sivori tiene una intuición clara y distinta, y se la formula como una pregunta: ¿es, La pasión, una película en tres partes sobre la precoz decisión de Eva de pasar a la historia, de convertirse en una leyenda, en un mito a través de su colosal obra social o es, puede o podría ser, La pasión, una película sobre la imposibilidad de realizar una película sobre Eva Perón? (2010, pp. 92-93).

En otros términos, podríamos decir que el proyecto fílmico de Sivori se diluye en "la brutal indiferencia que rige los primeros años del siglo XXI" del mismo modo en que el proyecto político de Eva quedó deshecho por su muerte prematura. Pero como afirmaba Jorge Torres Roggero, Evita también constituye "un símbolo permanente de las reivindicaciones populares" (1983, p. 3), y este carácter nos permite reconocer en su figura la esencia de aquello que Nicolás Casullo llamó "mito peronista”. En lo que se aproxima a una definición, Casullo señalaba que dicho mito:

en lo sustancial fusiona como relato hegemónico el encuentro entre una experiencia de justicia protagonizada por los sin voz, que el líder configura, expresa, como palabra concreta contra los que impiden que esa patria popular se realice: lo que permite un nuevo tipo de comprensión de la soberanía, de la democracia, de la institucionalidad y de la historia del país. [...] El mito peronista explica, aclara y proyecta de una manera inédita la historia del bien y del mal, de los amantes y malversadores de la nación. La experiencia de la dicha y la desdicha social (2008, p. 26).

Desde esta visión, más allá de que Evita sintetice al peronismo que no se dejó arrancar el alma que trajo de la calle ${ }^{20}$ y Perón muestre un sinnúmero de claroscuros, su proyecto político no halló en él a un rival sino a un aliado "contra los que impiden que (la) patria popular se realice" (Casullo, 2008, p. 26). En sus procesos de formación, países semicoloniales como el nuestro negaron a las alteridadades populares, obliterando la posibilidad de construir un Estado que las integrara. De allí que el "mito peronista" demande su reconocimiento para comprender de otro modo la soberanía, la democracia, la institucionalidad y la historia argentinas; y siendo a la vez emergente de un universo mítico forjado en la fisura entre civilización y barbarie, ese "mito" reclama la subalternización de las élites que, en los términos de Casullo (2008), "malversan la nación" y generan la "desdicha social" (p. 26). Partiendo de esta particular dinámica histórica podemos comprender desde otra perspectiva los motivos que en el contexto de una Argentina en crisis y de un peronismo que parecía haber muerto y arrastrado consigo a su mito, llevaban a Saítta a preguntarse si la potencialidad política de Eva había sido finalmente conjurada.

20 Parafraseamos aquí a la propia Eva Perón, que en Mi mensaje decía: "Yo no me dejé arrancar el alma que traje de la calle... Por eso no me deslumbró jamás la grandeza del poder, y pude ver sus miserias; y por eso nunca me olvidé de las miserias de mi pueblo y pude ver sus grandezas" (Perón, 2012, p. 27). 
Lejos de una conjuración definitiva, la revitalización que su figura, su obra, su mito y su mensaje fueron experimentando durante la década pasada a partir del surgimiento, consolidación y progresiva "peronización” del kirchnerismo (González, 2011, p. 56) parece señalar que mientras el "proyecto" de construir una "patria popular" no sea olvidado, el mito de Evita se obstinará en retornar para ofrendar su voz y ser bandera del pueblo empoderado.

Por su parte y a través de la saga analizada, Juan Martini posibilitó el reencuentro entre Eva Perón y aquel potencial alguna vez extraviado. Para hacerlo, apeló a la ficción literaria; tal como señalaba Jorge Consiglio en su presentación de Cine II:

\footnotetext{
el narrador parece entender que existen dos alternativas para sortear la condición de lo efímero: el mito y la ficción. Y, justamente, es Eva Perón el símbolo dentro del texto en el que se cruzan los caminos que funcionan como directrices. Eva Perón, dentro de este imaginario, no solo es diagramada sino también preservada por la ficción; consigue sortear, con el blindaje paradójico de su extrema vulnerabilidad, las rigideces de la piedra; el rigor de lo mineral $^{21}$ (2010, párr. 15).
}

Entrado el siglo XXI, Martini redescubrió el escurridizo mito de Eva. Un mito que se escurre, felizmente, porque se lo sigue narrando.

\section{Bibliografía}

Aira, C. (1998). La trompeta de mimbre. Rosario: Beatriz Viterbo Editora.

Avellaneda, A. (1983). El habla de la ideología. Buenos Aires: Sudamericana.

Baudrillard, J. (1991). La transparencia del mal. Barcelona: Editorial Anagrama.

Borges, J. L. (1998a). El hacedor. Madrid: Alianza Editorial.

Borges, J. L. (1998b). El Aleph. Madrid: Alianza Editorial.

Borroni, O. y Vacca, R. (1970). La vida de Eva Perón. Testimonios para su historia (Tomo I). Buenos Aires: Galerna.

De Mondonça, I. y Lafosse, J. P. (2006). Evita sobrevive. Archivos de la revista el interpretador. Recuperado de https://revistaelinterpretador.wordpress.com/2016/11/26/ evita-sobrevive-representaciones-de-eva-peron-en-la-literatura-argentina/

Campbell, J. (1972). El héroe de las mil caras. Psicoanálisis del mito. D.F.: Fondo de Cultura Económica.

Castiñeira de Dios, J. M. (2015). Eva Perón. El Avión Negro, (38), 42.

Casullo, N. (2008). Peronismo. Militancia y crítica (1973-2008). Buenos Aires: Colihue.

Consiglio, J. (2010). Sobre Cine II. Eterna Cadencia. Recuperado de https://eternacadencia. com.ar/blog/editorial/presentaciones/item/sobre-cine-ii.html

Echeverría, E. (1979). La cautiva. El matadero. Ojeada retrospectiva. Buenos Aires: Centro Editor de América Latina.

González, H. (2011). Kirchnerismo: una controversia cultural. Buenos Aires: Colihue.

Herrendorf, D. (2003). Evita, la Loca de la Casa. Buenos Aires: Editorial Sudamericana.

21 Esto se ponía de manifiesto en la primera novela, cuando el narrador aseveraba que "la ficción es la forma perdurable de lo real" (2009, p. 125). 
Martínez, T. E. (1995). Santa Evita. Buenos Aires: Planeta.

Martini, J. (2009). Cine. Buenos Aires: Eterna Cadencia.

Martini, J. (2010). Cine II - Europa, 1947. Buenos Aires: Eterna Cadencia.

Martini, J. (2011). Cine III - La inmortalidad. Buenos Aires: Eterna Cadencia.

Olivari, N. (24 de agosto de 1952). Ella. La Prensa. Buenos Aires: Argentina.

Perón, E. (2012). Mi mensaje. Rosario: Fundación Ross.

Pigna, F. (2012). Evita. Jirones de su vida. Buenos Aires: Planeta.

Pons, C. y Soria, C. (Eds.) (2005). Delirios de grandeza. Los mitos argentinos: memoria, identidad, cultura. Rosario: Beatriz Viterbo Editora.

Posse, A. (1994). La pasión según Eva. Buenos Aires: Emecé.

Rosano, S. (2006). Rostros y máscaras de Eva Perón. Imaginario populista y representación. Rosario: Beatriz Viterbo Editora.

Saítta, S. (17 de julio de 2002). De actriz a personaje literario. La Nación. Recuperado de www. lanacion.com.ar/221755-de-actriz-a-personaje-literario

Sacca, Z. (2003). Eva Perón, de figura política a heroína de novela. Quito: Ediciones Abya Yala/Universidad Andina Simón Bolívar.

Sarlo, B. (2003). La pasión y la excepción. Buenos Aires: Siglo Veintiuno Editores.

Sarmiento, D. F. (1979). Facundo. Buenos Aires: Centro Editor de América Latina.

Sebreli, J. J. (2008). Comediantes y mártires. Ensayo contra los mitos. Buenos Aires: Editorial Sudamericana.

Soria, C. (2005). Los cuerpos de Eva. Anatomía del deseo femenino. Rosario: Beatriz Viterbo Editora.

Susti González, A. (2007). "Seré millones”. Eva Perón: melodrama, cuerpo y simulacro. Rosario: Beatriz Viterbo Editora.

Torres Roggero, J. (1983). Eva Perón y la dignificación de la mujer. Buenos Aires: Instituto Leopoldo Marechal.

Zunini, P. (2010). Entrevista. "El proyecto de Evita era más socialista que peronista”. Sitio web de Juan Martini. Recuperado de https://sites.google.com/site/martinitaller/entrevistas 
